\title{
Guidelines for rainwater harvesting system design and assessment for the city of Johannesburg, South Africa
}

\author{
John Ndiritu, Adesola Ilemobade, and Paulo Kagoda \\ University of the Witwatersrand, School of Civil and Environmental \\ Engineering, 2050 Johannesburg, South Africa \\ Correspondence: John Ndiritu (john.ndiritu@wits.ac.za)
}

Received: 1 January 2018 - Revised: 21 February 2018 - Accepted: 22 February 2018 - Published: 5 June 2018

\begin{abstract}
As water demand increases rainwater harvesting (RWH) systems are increasingly being installed for water supply but comprehensive hydrologic design guidelines for RWH do not exist in many parts of the world. The objective of this study was to develop guidelines for the hydrologic design and assessment of rainwater harvesting (RWH) systems in the City of Johannesburg, South Africa. The data for developing the guidelines were mainly obtained from multiple daily simulations of potential RWH systems in the city. The simulations used daily rainfall from 8 stations and demands based on the probable non-potable uses of RWH systems - toilet flushing, air conditioning and irrigation. The guidelines were confined to systems that would typically fill up in the wet season and empty towards the end of the dry season of the same year. Therefore, supply-to-demand ratios ranging from 0.1 to 0.9 were applied. Two generalized design charts of dimensionless relationships were developed. One relates the yield ratio with supply-to-demand ratio and reliability while the other relates the yield ratio with the storage-to-demand ratio and reliability. Reliability was defined as the probability of exceedance of annual yield in order to incorporate the large inter-annual variability of rainfall experienced in the region. The analyses and design of an example RWH system is used to illustrate the application of the design charts.
\end{abstract}

\section{Introduction}

Significant population and industrial growth are expected in the City of Johannesburg (CoJ) over the next decade. Therefore, implementing Water Conservation and Demand Management Strategies to enhance water security are current requirements for a sustainable environment. The CoJ considers Rainwater Harvesting (RWH) as a potential source of supply and intends to encourage its use. RWH is generally perceived to be relatively cheaper; simpler to install, operate and maintain; and environmentally more friendly than many other water resource alternatives. It is also essential in Water Sensitive Urban Design as it reduces urban runoff (Armitage et al., 2014) which, could also lead to a reduction in pollutant levels entering receiving waterways (McAlister, 2007). The quality of rainwater is usually superior to surface water and groundwater that may have been contaminated (van der Sterren et al., 2012) although rainwater may not always meet drinking water standards (Evans et al., 2006; Dobrowsky et al., 2014). This paper describes the development of guide- lines for the hydrologic design and assessment of RWH systems for the CoJ. This is achieved by developing generalized relationships of the main components of the RWH systems expected to be installed in the CoJ.

\section{Materials and methods}

The RWH system variables included in the generalization are storage size, catchment area, the rainfall, the yield and its reliability. Relationships amongst these variables were obtained using data from daily time-step simulations of potential RWH systems in the CoJ and the selection of this data applied the concept of hydrologic optimality. A hydrologically optimal RWH system lies on the Pareto front at which storage size is minimized while yield and reliability are maximized (Ndiritu et al., 2017). The RWH system variables required to determine this are the catchment area, the rainfall, the tank size, the demand, the yield and its reliability. The development of the guidelines was based on the numerical data 


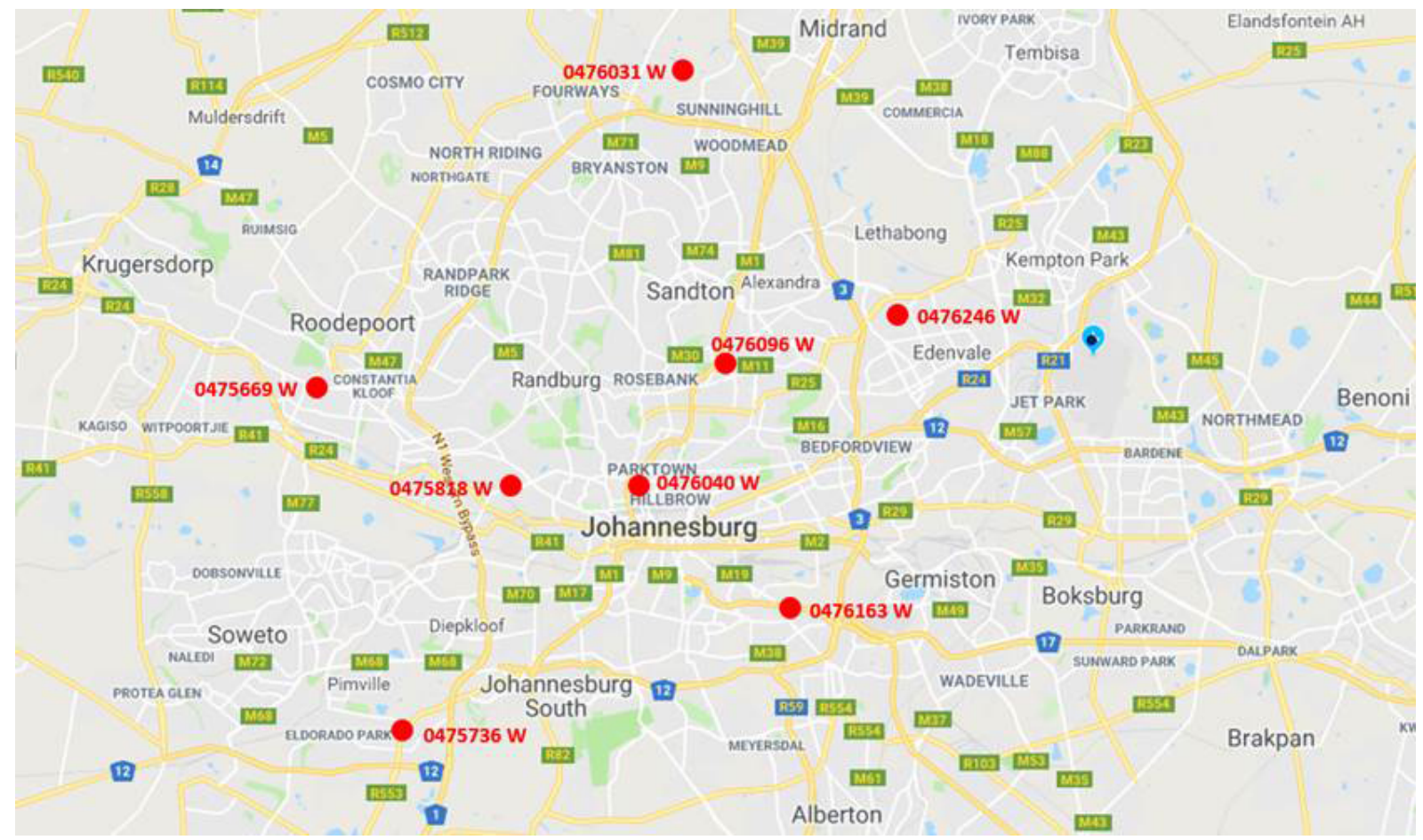

Figure 1. Location of rainfall stations.

of these variables obtained from daily time step simulations of the RWH systems that are likely to be installed in the CoJ. Hanson and Vogel (2014), Campisano and Modica (2012) and Liaw and Chiang (2014) also used simulation to develop generalised methods of RWH analysis. Equations (1) and (2) describe the yield-after-spillage daily water balance simulation that was applied in the study.

$$
\begin{array}{ll}
R_{e}(t)=\begin{array}{ll}
D(t) & \text { if } S(t) \geq D(t) \\
S(t) & \text { if } S(t)<D(t)
\end{array} \\
S(t+1)=\min \begin{array}{l}
C-R_{e}(t) \\
S(t)+\eta R(t) A-R_{e}(t)
\end{array}
\end{array}
$$

where $R_{e}(t)$ is the volume of water released to meet the demand in period $t, D(t)$ is the demand in period $t, S(t)$ is the volume of water in storage at the start of period $t, C$ is the live storage capacity of the tank, $\eta$ is the water collection efficiency, $R(t)$ is the rainfall intensity in period $t$ and $A$ is the horizontal projection of the effective roof area.

The quantity and variability of the water available for collection depends on the rainfall available, the roof area and the efficiency of collection. In order to allow for variability of rainfall, 8 raingauge stations spread out across the $\mathrm{CoJ}$ (Fig. 1) with long duration and reliable rainfall data were selected for analysis (Table 1). The guidelines needed to be applicable to situations of low, average and high demand. Therefore a wide range of the ratio of available supply to demand was applied by varying the catchment area for a set demand. Various field studies have obtained rainwater col-
Table 1. Rainfall station information.

\begin{tabular}{lccc}
\hline $\begin{array}{l}\text { Station } \\
\text { number }\end{array}$ & $\begin{array}{c}\text { Period } \\
\text { of data }\end{array}$ & $\begin{array}{c}\% \text { Cont. } \\
\text { data }\end{array}$ & $\begin{array}{c}\text { Mean } \\
\text { annual } \\
\text { rainfall } \\
\left(\mathrm{mm} \mathrm{yr}^{-1}\right)\end{array}$ \\
\hline 0475669 W & $1886-1993$ & 99 & 715 \\
$0475736 \mathrm{~W}$ & $1886-2011$ & 91 & 655 \\
$0475818 \mathrm{~W}$ & $1886-2015$ & 88 & 719 \\
$0476031 \mathrm{~W}$ & $1886-2017$ & 91 & 654 \\
$0476040 \mathrm{~W}$ & $1886-2017$ & 89 & 783 \\
$0476096 \mathrm{~W}$ & $1886-2017$ & 81 & 615 \\
$0476163 \mathrm{~W}$ & $1886-2005$ & 92 & 719 \\
$0476246 \mathrm{~W}$ & $1886-2000$ & 93 & 705 \\
\hline
\end{tabular}

lection efficiencies ranging from 80-90\% (Mashau, 2006; Liaw and Tsai, 2004) and a constant rainwater collection efficiency of $80 \%$ was applied. The generalized guidelines were however formulated to be applicable with any collection efficiency. The simulations were also run for a wide range of tank capacities for each combination of roof area and demand in order to ensure that the hydrologically optimal combinations of the variables are obtained. The various RWH demands expected in CoJ have distinct distributions at various time scales and the effects of this variability needed to be incorporated into the guidelines. Domestic household demand is typically constant throughout the year while day school human demand (toilet flushing and handwashing) is 


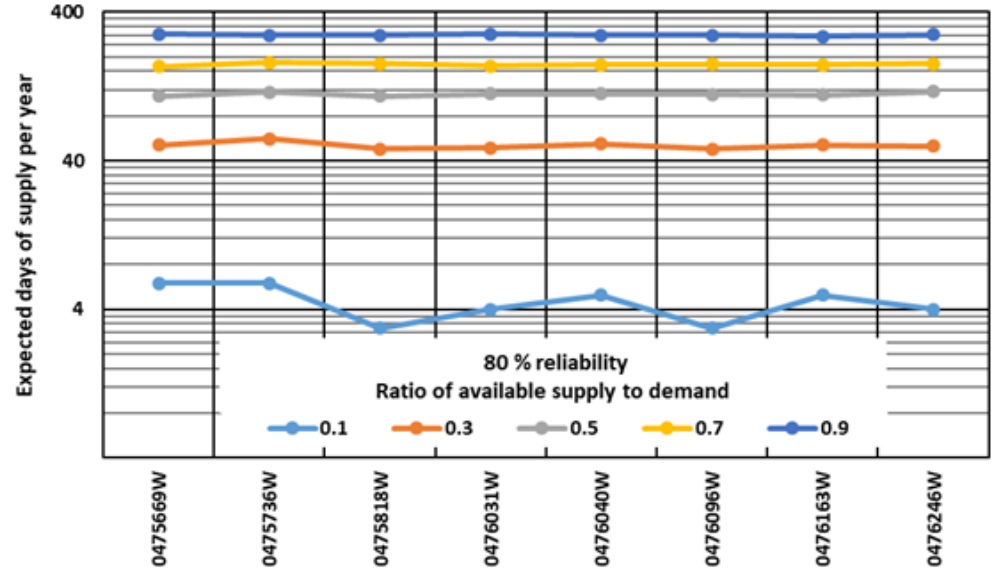

Figure 2. Typical variation of days of supply for different rainfall stations.

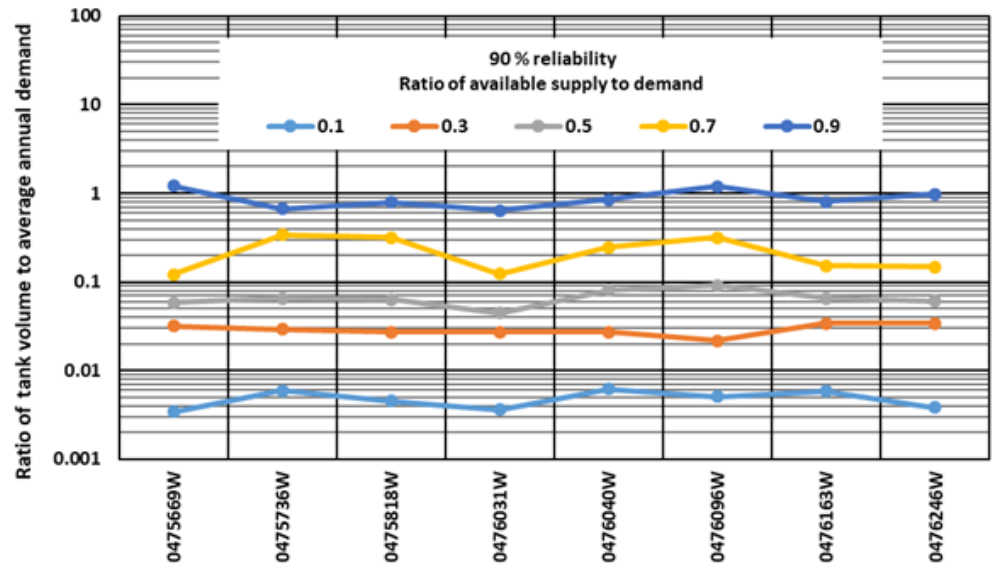

Figure 3. Typical variation of tank volume to demand ratio for different rainfall stations.

higher on weekdays and lower in the non-schooling months of the year. On the contrary, Shopping mall human demand is higher in the weekends and the holiday periods of the year. Irrigation and HVAC (air conditioning) demand vary with seasonal temperature. Irrigation demand additionally varies with antecedent catchment wetness which is rainfall-dependent. Trial simulation runs indicated that increasing the variation of seasonal demand reduced yields (levels of supply). This variation was however found not to impact optimal tank size. Therefore, it was decided to develop the guidelines using the yields obtained from the HVAC/irrigation type demand variation and the largest optimal tank sizes obtained from any distribution of demand. This was considered a way of incorporating safety margins and a reduction of the risk of undersizing system components.

\section{The development of design guidelines}

Trial runs indicated that for specific ratios of available supply to demand, the yield (number of days the demand is met per year) did not vary appreciably for the different raingauge stations (Fig. 2). This is in agreement with similar observations made for raingauging stations spread over much larger areas of South Africa (Ndiritu et al., 2014, 2017). The variation of the ratios of optimal tank storage to demand varied more appreciably (Fig. 3) but these ratios were found not to correlate with rainfall characteristics $\left(R^{2}<0.10\right)$ or location within the CoJ. It was therefore decided to develop generalized guidelines that are independent of location within the CoJ by averaging the optimal variables obtained from simulations using the 8 stations. For each rain gauge station data, daily time step simulations were carried out for available supply to demand ratios of $0.1,0.3,0.5,0.7$ and 0.9 and the optimal tank volume obtained for reliabilities of 50, 66.7, 80, 90,95 and $98 \%$. The respective levels of assurance (probability of exceedance) of days of supply for these reliabilities are 1 in 2 years, 2 in 3 years, 4 in 5 years, 9 in 10 years, 19 in 20 years and 49 in 50 years. Many RWH systems are likely to be complementary (and not the main water supply sources) in the $\mathrm{CoJ}$ in which case they therefore would not need to sup- 

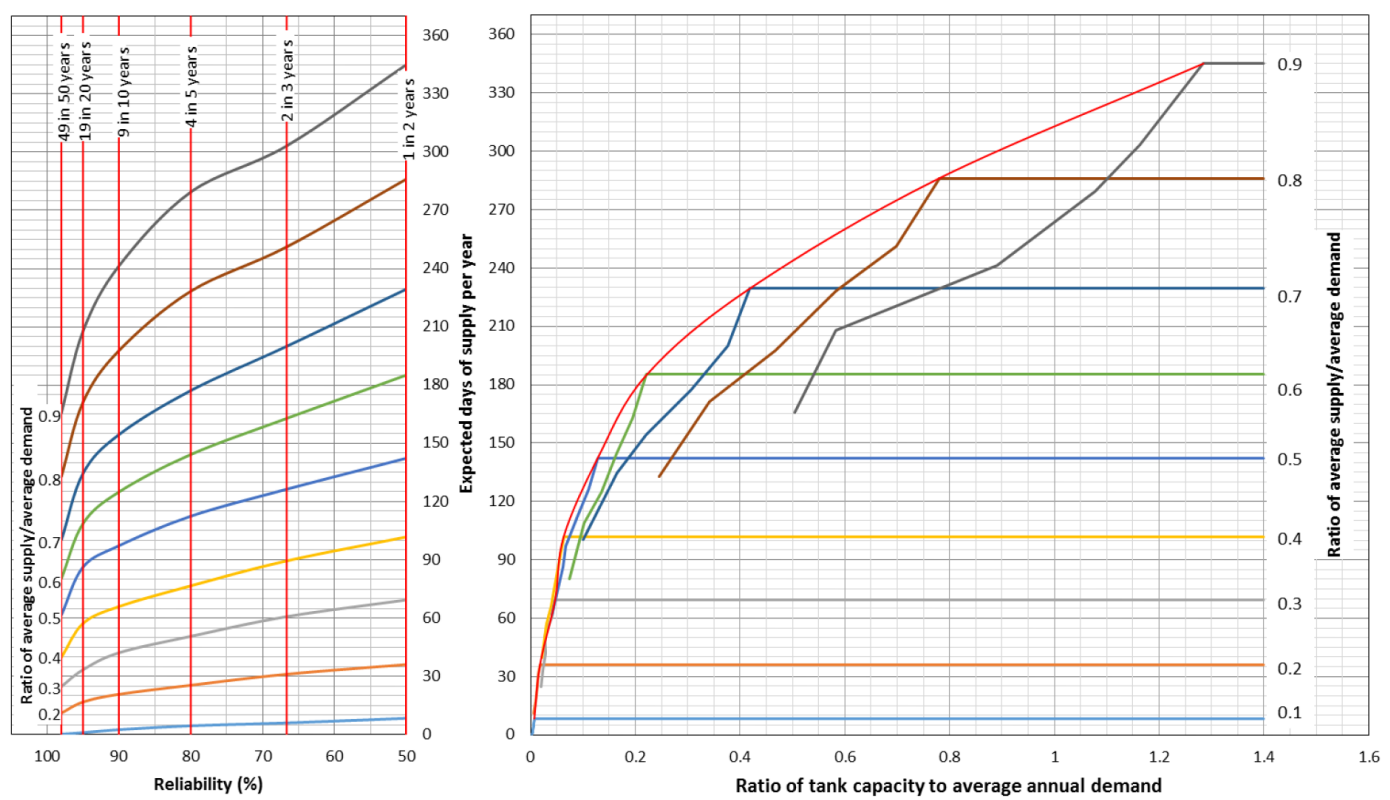

Figure 4. Generalised rainwater harvesting design and assessment charts for Johannesburg.

ply water at the high reliabilities ( $\geq 90 \%$ ) the overall supply typically requires. Therefore, it was decided to include reliabilities as low as $50 \%$ for the generalization. For probabilistic life cycle or other cost analyses, the expected long-term supply levels correspond to $50 \%$ reliability and generalized guidelines that include this seemingly low reliability would therefore be applicable.

The generalization followed the approach applied by Ndiritu et al. (2017) and was carried out in two steps: (i) finding appropriate non-dimensionless ratios of the optimal hydrologic components obtained from the simulations, and (ii) graphically presenting the relationships of these nondimensionless ratios and other variables efficiently to obtain design charts. The resulting design charts are presented in Fig. 4. The design charts can be used to size a proposed RWH system or to assess the performance of an existing system and the alternatives for its enhancement. An example illustrating the application of the charts is presented in Sect. 4.

\section{Example of application of guidelines}

The following hypothetical but realistic example is used to illustrate the application of the RWH design charts. The grass in a $10000 \mathrm{~m}^{2}$ recreation park has an annual consumptive use of $870 \mathrm{~mm} \mathrm{yr}^{-1}$ and $15 \%$ of this is met by rainfall while the rest needs to be provided by irrigation. The City of Johannesburg Parks Department is considering using the stormwater that drains from a nearby housing estate for this. This estate covers an area of $15850 \mathrm{~m}^{2}$ and it is estimated that $60 \%$ of the rain falling over this area could be captured as stormwater for irrigation. There is a reservoir of capacity $2590 \mathrm{~m}^{3}$ available for storing the harvested stormwater. What would be the expected yield of the system? How can the system's yield (expected days of supply per year) be maximized? The MAR for the area is $700 \mathrm{~mm} \mathrm{yr}^{-1}$.

The ratio of available supply to demand

$$
=\frac{15850 \times 700 / 1000 \times 0.6}{10000 \times 870 / 1000 \times(1-0.15)}=0.90
$$

The ratio of tank capacity to demand

$$
=\frac{2590}{10000 \times 870 / 1000 \times(1-0.15)}=0.35
$$

The supply ratio of 0.9 has a minimum ratio of tank capacity to demand of 0.50 (Fig. 5) and the available capacity of $2590 \mathrm{~m}^{3}$ can therefore not be optimal at any reliability. This means that some of the stormwater supply would not be utilized.

The maximum ratio of available storage to demand that the existing tank with a tank capacity to demand ratio of 0.35 can utilize is 0.67 (Fig. 5).

This would mean that the area of the housing estate that would need to be drained into the $\operatorname{tank}=\frac{0.67}{0.90} \times 15850=11799 \mathrm{~m}^{2}$.

As illustrated on Fig. 5, this would give yields (expected days of supply) of 205, 185, 165, 145, 125 and 95 at assurances of 1 in 2,2 in 3, 4 in 5, 9 in 10, 19 in 20 and 49 in 50 years respectively.

If the whole area of the housing estate is drained, supply can be maximized by installing additional storage to give a tank volume to demand ratio of 1.275 (Fig. 5). The required extra storage would then be $\left(\frac{1.275-0.35}{0.35}\right) \times 2590=6845 \mathrm{~m}^{3}$. 


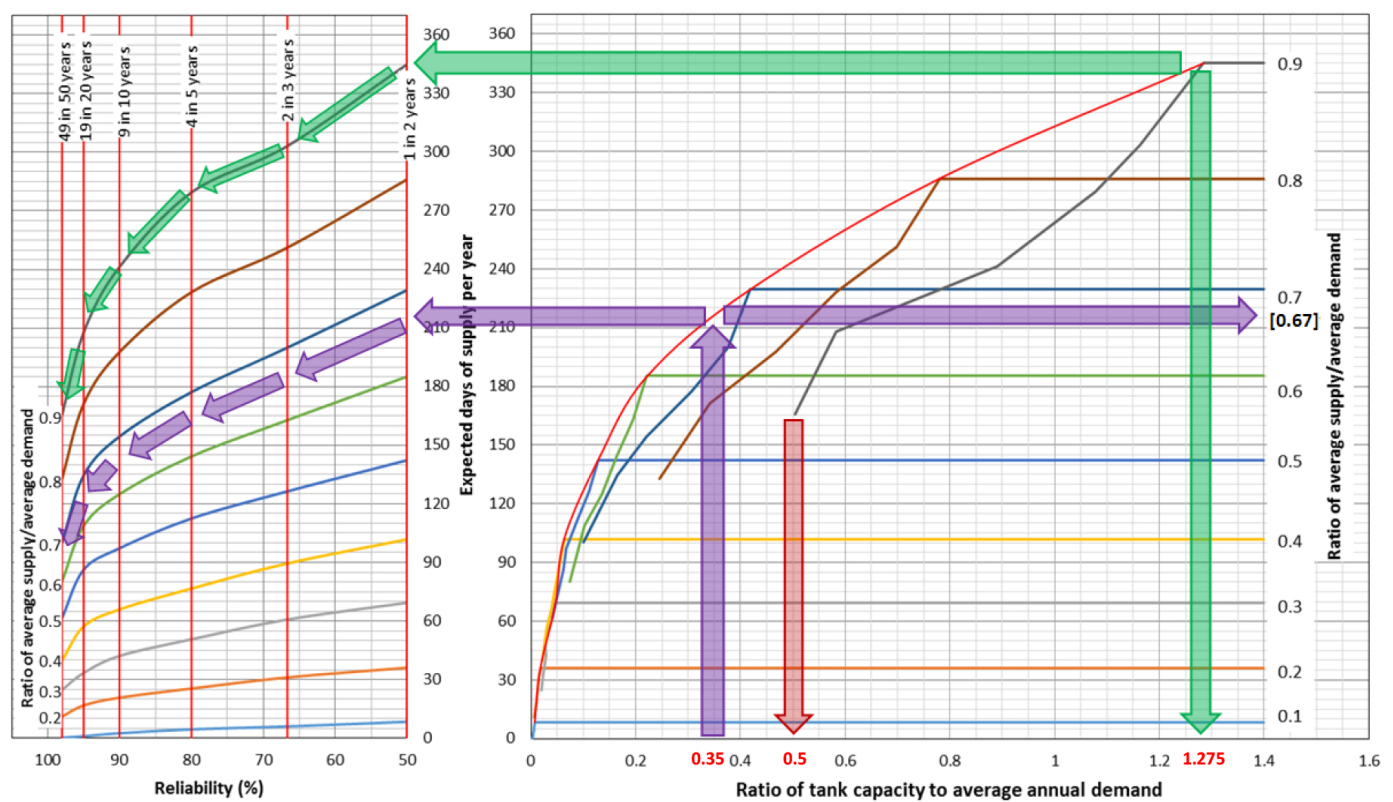

Figure 5. Example of application of rainwater harvesting sizing and assessment chart.

This would provide expected days of supply of 345,305 , 280, 240, 210 and 165 at 1 in 2, 2 in 3, 4 in 5, 9 in 10, 19 in 20 and 49 in 50 levels of assurance respectively.

\section{Conclusions}

Guidelines for hydrologic rainwater harvesting $(\mathrm{RWH})$ design and assessment for the City of Johannesburg (CoJ) have been developed and their application to a realistic RWH problem has been demonstrated. The guidelines could be enhanced by including more rainfall records in their formulation and by including design and assessment of hydrologically non-optimal RWH systems as demonstrated by Ndiritu et al. (2017). The current guidelines are however considered adequate for the preliminary design and assessment of feasibility of RWH systems in the City of Johannesburg. A numerical version of the design charts can be formulated to enable computer-based design and assessment of RWH systems in the CoJ.

Data availability. The rainfall data for this study was obtained from Lynch (2003).

Competing interests. The authors declare that they have no conflict of interest.

Special issue statement. This article is part of the special issue "Innovative water resources management - understanding and balancing interactions between humankind and nature". It is a result of the 8th International Water Resources Management Conference of ICWRS, Beijing, China, 13-15 June 2018.

Edited by: Zongxue Xu

Reviewed by: two anonymous referees

\section{References}

Armitage, N., Fisher-Jeffes, L., Carden, K., Winter, K., Naidoo, V., Spiegel, A., Mauck, B., and Coulson, D.: Water Sensitive Urban Design (WSUD) for South Africa: Framework and Guidelines, WRC Report No. TT 588/14, Water Research Commission, Pretoria, South Africa, 2014.

Campisano, A. and Modica, C.: Optimal sizing of storage tanks for domestic rainwater harvesting in Sicily, Resour. Conserv. Recycl., 63, 9-16, https://doi.org/10.1016/j.resconrec.2012.03.007, 2012.

Dobrowksy, P. H., Mannel, D., De Kwaadsteniet, M., Prozesky, H., Khan, W., and Cloete, T. E.: Quality assessment and primary uses of harvested rainwater in Kleinmond, South Africa, Water SA, 40, 401-406, https://doi.org/10.4314/wsa.v40i3.2, 2014.

Evans, C. A., Coombes, P. J., and Dunstan, R. H.: Wind, rain and bacteria: the effect of weather on the microbial composition of roof-harvested rainwater, Water Res., 40, 37-44, 2006.

Hanson, L. S. and Vogel, R. M.: Generalized storage-reliabilityyield relationships for rainwater harvesting systems, Environ. Res. Lett., 9, 1-10, https://doi.org/10.1088/17489326/9/7/075007, 2014.

Liaw, C. and Tsai, Y.: Optimum Storage Volume of Rooftop Rain Water Harvesting Systems for Domestic Use, J. Am. Water Resour. Assoc., 40, 901-912, https://doi.org/10.1111/j.17521688.2004.tb01054.x, 2004. 
Liaw, C. H. and Chiang, Y. C.: Dimensionless analysis for designing domestic rainwater harvesting systems at the regional level in Northern Taiwan, Water, 6, 3913-3933, https://doi.org/10.3390/w6123913, 2014.

Lynch, S.: The Development of a Raster Database of Annual, Monthly and Daily Rainfall for Southern Africa, WRC Report No. 1156/0/1, Water Research Commission, Pretoria, South Africa, 2003.

Mashau, F.: Rainwater Harvesting for Multiple Uses in Siloam Village of Limpopo Province, South Africa; Unpublished Honours Research Dissertation, University of Venda, Thohoyandou, South Africa, 2006.

McAlister, T.: National Guidelines for Evaluating Water Sensitive Urban Design, BMT WBM, Brisbane, Australia, 2007.
Ndiritu, J. G., McCarthy, S., and Tshirangwana, N.: Probabilistic assessment of the rainwater harvesting potential of schools in South Africa, Proc. IAHS, 364, 435-440, https://doi.org/10.5194/piahs-364-435-2014, 2014.

Ndiritu, J., Yashiren, M., and Guliwe, M.: Generalized StorageYield-Reliability Relationships for Analysing Shopping Centre Rainwater Harvesting Systems, Water, 9, 1-20, https://doi.org/10.3390/w9100771, 2017.

van der Sterren, M., Rahman, A., and Dennis, G. R.: Rainwater Harvesting Systems in Australia, in: Ecological Water Quality Water Treatment and Reuse, edited by: Voudouris, K., INTECH, Rijeka, Croatia, 2012. 